\title{
BMJ Open Statin use and risk of liver cancer: an update meta-analysis
}

\author{
Meng Shi, Huiling Zheng, Biao Nie, Wei Gong, Xiaobing Cui
}

To cite: Shi M, Zheng $\mathrm{H}$, Nie B, et al. Statin use and risk of liver cancer: an update meta-analysis. BMJ Open 2014;4:e005399. doi:10.1136/bmjopen-2014005399

- Prepublication history and additional material is available. To view please visit the journal (http://dx.doi.org/ 10.1136/bmjopen-2014005399).

Received 4 April 2014 Revised 8 August 2014 Accepted 11 August 2014

CrossMark

Guangdong Provincial Key Laboratory of

Gastroenterology, Department of Gastroenterology, Nanfang Hospital, Southern Medical University, Guangzhou, China

Correspondence to Dr Xiaobing Cui; xbing119@gmail.com

\section{ABSTRACT}

Objective: Statins are commonly prescribed

cholesterol-lowering drugs. Preclinical studies suggest that statins may possess cancer preventive properties. The primary objective of this meta-analysis was to determine the association between statin use and risk of liver cancer.

Design: Meta-analysis.

Setting: International.

Participants: A comprehensive literature search of PubMed, BIOSIS Previews, Web of Science, EMBASE, EBSCO and Cochrane Library was conducted through March 2014. The effect estimate was reported as pooled relative risk (RR) with $95 \% \mathrm{Cls}$, using the random-effects model.

Results: A total of 12 studies ( 1 individual patient data analysis of 22 randomised controlled trials, 5 cohorts and 6 case-controls) were qualified for this meta-analysis, involving 5640313 participants including 35756 liver cancer cases. Our results indicated a significant risk reduction of liver cancer among all statin users ( $\mathrm{RR}=0.58,95 \% \mathrm{Cls} 0.51$ to $0.67)$. The difference of the study designs can partly explain the significant heterogeneity found in the overall analysis $\left(\mathrm{I}^{2}=65 \%, \mathrm{p}=0.0006\right)$. No evidence of publication bias was observed in this meta-analysis. Similar risk reductions were found in the subgroups analysis of Western and Asian countries, lipophilic and hydrophilia statins. There was a trend towards more risk reductions in subgroups with higher baseline risk, inadequate adjustment and higher cumulative dosage of statin use.

Conclusions: This meta-analysis suggests that statin is associated with a significant risk reduction of liver cancer when taken daily for cardiovascular event prevention. However, this preventive effect might be overestimated due to the exposure period, the indication and contraindication of statins and other confounders. Statins might be considered as an adjuvant in the treatment of liver cancer.

\section{INTRODUCTION}

Statins are inhibitors of 3-hydroxy-3methylglutaryl coenzyme-A (HMG-CoA) reductase, widely used to reduce plasma cholesterol levels and the risk of cardiovascular events. ${ }^{1}$ Although there is a concern over their possible carcinogenicity raised in

\section{Strengths and limitations of this study}

- Statins are commonly prescribed as cholesterollowering drugs. In this comprehensive meta-analysis, we demonstrate that statin use is associated with a significant risk reduction of liver cancer.

- The difference of the study designs is part of the reason explaining the significant heterogeneity found in the overall analysis.

- However, this preventive effect might be overestimated due to the exposure period, the indication and contraindication of statins and other confounders.

- Statins might be considered as an adjuvant in the treatment of liver cancer.

rodent studies, ${ }^{2}$ preclinical studies indicate that statins have anticancer properties in vitro and in vivo, through inhibiting angiogenesis, inducing apoptosis, and suppressing tumour growth and metastasis. ${ }^{3-5}$

However, higher concentrations of statins are typically required to induce these effects, raising questions concerning the therapeutic relevance of statins on cancer. ${ }^{6}$ To date, clinical studies regarding the cancer incidence associated with statin administration have highlighted conflicting results. Moreover, a large number of meta-analyses have concluded that there was no association between statin use and risk of overall cancer, ${ }^{7-10}$ or cancer of breast, ${ }^{11}$ stomach $^{12}$ or pancreas. ${ }^{13}$ There is only a modest protective effect of statins in prostate cancer ${ }^{14}$ and colorectal cancer. $^{15}$

On the contrary, recent studies reported encouraging results for risk reduction of liver cancer among all statin users. Previous meta-analysis, conducted by Singh et $a l^{16}$ through including 10 studies, found that statin users were less likely to develop hepatocellular carcinoma (HCC) than statin non-users. However, Singh et al included the ALERT, LIPS and MEGA trials twice by including three individual patient data (IPD) analysis of randomised controlled trials (RCTs). ${ }^{17-19}$ Meanwhile, some factors of 
stratification were not considered in their analyses, such as dose and timing of exposure to statins, and the selection of controls and confounders, which might limit the evaluation of cancer risk. ${ }^{20}$ Furthermore, lipophilic statins are accompanied by an extensive first-pass effect at the hepatic level. ${ }^{21}$ It is plausible that lipophilic statins may have better liver cancer preventive qualities than hydrophilic statins. ${ }^{22}$

Therefore, we performed this updated meta-analysis to assess the association between statin use and risk of liver cancer, involving the recently published studies and conducting more subgroup analyses based on the factors aforementioned. Our results demonstrated that statin use was associated with an over $40 \%$ risk reduction in liver cancer, which may have a significant translational potential in clinical practice. However, there were some confounders that might overestimate this preventive effect of statins.

\section{MATERIALS AND METHODS \\ Literature search strategy}

This meta-analysis was conducted following the PRISMA guidelines. $^{23}$

The systematic computerised search for eligible studies were performed on the database of PubMed, BIOSIS Previews, Web of Science, EMBASE, EBSCO and Cochrane Library, covering all studies published from their inception to 5 March 2014. The following terms were searched with the subjects (MeSH terms) as well as text-word search strategies: "(Statin OR HMG-CoA reductase inhibitors OR Atorvastatin OR Cerivastatin OR Fluvastatin OR Lovastatin OR Pravastatin OR Rosuvastatin OR Simvastatin) AND (Hepatocellular OR Hepatic OR Intrahepatic OR Interlobular OR Liver) AND (Carcinoma OR Sarcomas OR Angiosarcoma OR Cancer OR Neoplasm). Additionally, the relevant reviews and retrieved articles were searched manually for more eligible studies.

In study searching, only the original researches, published in the form of peer review articles or meeting abstracts, were included. No language restrictions were imposed. However, the studies we included were all published in English.

\section{Study selection}

The inclusion criteria were: (1) RCTs, cohort studies or case-control studies; (2) original studies that assessed the effect of statin use on the risk of liver cancer, compared with placebo or no treatment; (3) liver cancer cases identified according to the International Classification of Diseases codes (ICD) and (4) studies with estimate of relative risk (risk ratio, RR) of liver cancer, or with data sufficient to calculate it.

The exclusion criteria were: (1) study design not meeting the inclusion criteria; (2) studies without estimate of RR, or without sufficient data to calculate it or (3) studies with duplicated or overlap reports.

\section{Data extraction}

Two independent investigators (MS and $\mathrm{XC}$ ) extracted data from the eligible studies using a predefined data collection form. The differences of data extraction were resolved by consensus referring back to the original article. The extracted information included: (1) studies: first author, year of publication, study design, location, patient populations, period and follow-up; (2) statins: type, dosage or duration of statin use and (3) liver cancer: case identification, number of liver cancers, crude RR with $95 \%$ CIs, adjusted RR reflecting the greatest degree of control for confounders and confounders for adjustment (including variables for matching). When the RR data were not available, the RR with $95 \%$ CIs were calculated from the raw data in original studies.

We extracted different measurements of effect estimates from original studies, such as RR, OR, HR and Observed/Expected ratio. Owing to the fact that the incidence of liver cancer was low in all studies, these different measurements can be used to provide similar estimates of RR.

\section{Methodological quality assessment}

Of note, the included RCT was pooled analysis of other RCTs, therefore it is inappropriate to assess the methodological quality. The methodological quality of cohort and case-control studies were assessed on the Newcastle-Ottawa Scale,${ }^{24}$ including eight items that were categorised into three categories: selection (four items, one star each), comparability (one item, up to two stars) and exposure/outcome (three items, one star each). A 'star' presents a 'high'-quality choice of each item.

\section{Statistical analysis}

The overall meta-analysis was first performed, followed by the subgroup analyses, based on study design, baseline risk of liver cancer, confounding adjustment, study location and pharmacokinetics. Meanwhile, we conducted subgroup analyses based on studies that reported RR estimates for higher cumulative dosage of statin use, when appropriate data were available.

To take into account the heterogeneity and provide a more conservative estimate, the inverse variance method was used to estimate the pooled RRs and corresponding 95\% CIs, and data were pooled using a random effects model. Heterogeneity was assessed using the $\chi^{2}$ statistic (P) together with the Higgins $\mathrm{I}^{2}$ statistic $\left(\mathrm{I}^{2}\right)$, a $\mathrm{p}$ value $<0.10$ was considered statistically significant for heterogeneity; and an $\mathrm{I}^{2}$ value $>50 \%$ was considered a measure of severe heterogeneity. ${ }^{25}$

Publication bias was assessed using the Begg's test and the Egger's test. ${ }^{26}$ Influence analysis was performed to investigate the influence of a single study on the overall meta-analysis estimate, by omitting one study in each turn. Test for interaction was applied to identify the difference between pooled RRs from subgroup analysis using the method described by Altman and Bland. ${ }^{27}$ All statistical tests were two-sided and $\mathrm{p}<0.05$ was considered 
statistically significant, unless otherwise specified. Software Review Manager (RevMan5.2, Copenhagen) and STATA (Stata V.11.2, Texas, USA) were used for the statistical analysis.

\section{RESULTS}

\section{Study selection}

Figure 1 illustrates the process of study selection for the meta-analysis. Of the 1424 potentially relevant references identified by electric and manual search, 142 were selected for full-text review after screening titles and abstracts. Finally, a total of 12 studies were included, with one IPD analysis, ${ }^{19}$ five cohort studies, ${ }^{28-32}$ and six casecontrol studies. ${ }^{33-38}$ One case-control study was presented solely in abstract form. ${ }^{33}$

Of note, the cohort study conducted by Friedman et $a l^{29}$ reported RR estimates separately for different genders (male and female), we considered these two reports as separate studies. Therefore, a total of 13 reports were included for the present meta-analysis.

\section{Study characteristics}

Table 1 summarises the characteristics of qualified studies in this meta-analysis. The 12 studies, involving 5640313 participants with 35756 liver cancer cases, were published between 2005 and 2013. The 'RCT' in the present study was pooled analysis of 22 clinical trials, ${ }^{19}$ which investigated statin therapy in cardiovascular event prevention and reported the occurrence of liver cancer as an adverse event. The observational studies were conducted with the local or national health databases, statin exposures were identified by linkage to

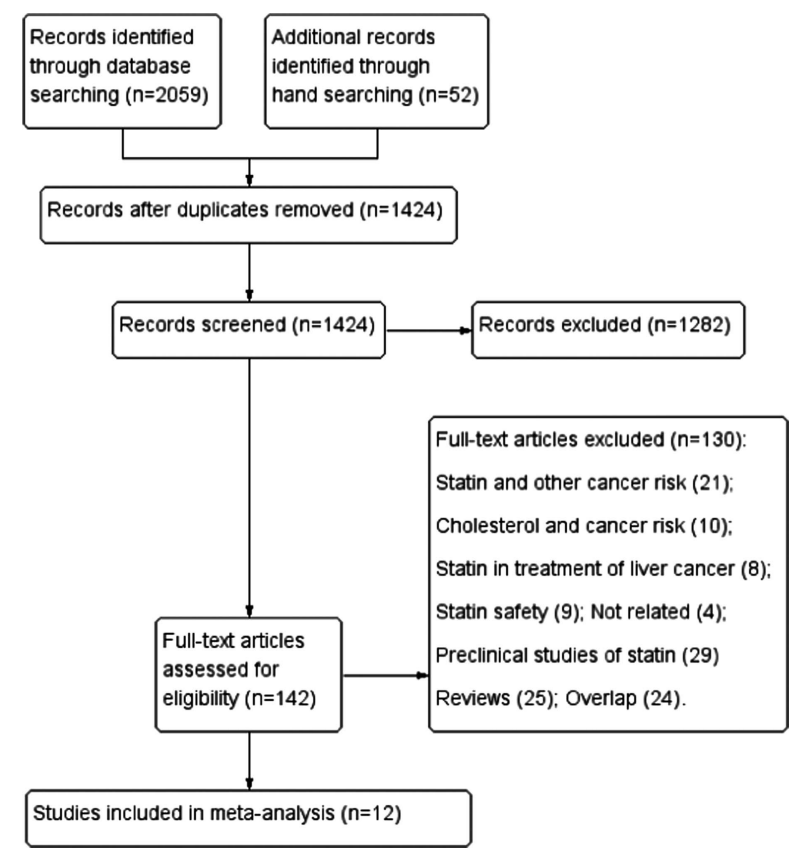

Figure 1 Flow chart of study selection in the present meta-analysis. prescription databases, and the controls were matched mainly by age, sex and index date. Except for one cohort, which adopted ICD-10 C22, ${ }^{28}$ all other studies identified liver cancer cases according to the ICD-9 155. Of note, two cohorts were restricted to patients with hepatitis $\mathrm{B}$ virus $(\mathrm{HBV})^{31}$ and hepatitis $\mathrm{C}$ virus (HCV) infections ${ }^{32}$; one case-control only included patients with diabetes mellitus ${ }^{34}$; and two observational studies included patients aged at least 45 years. ${ }^{30} 35$

Table 2 summarises the data of the included studies. In the $\mathrm{RCT}^{19}$ and one cohort study, ${ }^{30}$ the RR with $95 \%$ CIs were calculated from the $2 \times 2$ tables defined by the incidence of liver cancer and statin use status. The observational studies reported different measurements of RR estimates with adjustment by confounders. Several observational studies adopted the important risk factors of liver cancer for adjustments, ${ }^{31}{ }^{32}{ }^{34-36}$ such as HBV infection, HCV infection, cirrhosis and alcoholic liver disease or non-alcoholic fatty liver disease (NAFLD).$^{39}$ Of note, only two studies adjusted for cholesterol level, ${ }^{30} 38$ and no study adjusted for metabolic syndrome, which might also influence the risk of liver cancer. ${ }^{39}$

\section{Methodological quality}

For the cohort and case-control studies, the median score was 7 on the Newcastle-Ottawa Scale, with a range 5-8 (see online supplementary table S1). These results indicated that the observational studies were of a reasonably good quality.

\section{Overall meta-analysis}

Figure 2 depicts the forest plot of RR estimate with 95\% CIs from individual studies and overall meta-analysis. In the overall meta-analysis, pooled results showed a statistically significant decrease in liver cancer risk among all statin users ( $\mathrm{RR}=0.58,95 \%$ CIs 0.51 to 0.67$)$. Of note, a statistically significant heterogeneity was observed $\left(\mathrm{I}^{2}=65 \%, \mathrm{p}=0.0006\right)$. The $\mathrm{p}$ values of Begg's test and Egger's test were 0.669 and 0.749 , respectively, both suggesting there was no evidence of publication bias. In the influence analysis, the omission of any individual studies did not alter the direction and magnitude of the observed effect (see online supplementary figure S1).

\section{Subgroup analyses and test for interaction}

We first performed preplanned subgroup analyses based on study design, baseline risk of liver cancer, confounding adjustment and study location (table 3 ).

The RCT showed there is no significant association between statin use and risk of liver cancer $(R R=1.06$, 0.66 to 1.71 ). But the observational studies indicated a significant decrease of liver cancer risk among all statin users $\left(\mathrm{RR}=0.57,0.50\right.$ to $0.64 ; \mathrm{I}^{2}=61 \%, \mathrm{p}=0.003$; figure 2 ). Furthermore, we found a greater risk reduction in the subgroup analysis of cohort studies $(\mathrm{RR}=0.51,0.44$ to $\left.0.58 ; \mathrm{I}^{2}=18 \%, \mathrm{p}=0.30\right)$ than in the case-control studies $\left(\mathrm{RR}=0.63,0.54\right.$ to $0.73 ; \mathrm{I}^{2}=46 \%, \mathrm{p}=0.10$; see online supplementary figure $\mathrm{S} 2$ ). 
Table 1 Study characteristics

\begin{tabular}{|c|c|c|c|c|c|c|c|}
\hline Studies & $\begin{array}{l}\text { Study } \\
\text { design }\end{array}$ & Patient population & $\begin{array}{l}\text { Study } \\
\text { period }\end{array}$ & Cases defined & $\begin{array}{l}\text { Follow-up } \\
\text { (years) }\end{array}$ & Statin types & $\begin{array}{l}\text { Dosage/duration } \\
\text { of statin use }\end{array}$ \\
\hline Emberson et al, ${ }^{19} \mathrm{UK}$ & $\mathrm{RCT}$ & IPD analysis of 22 RCTs & - & ICD-9 155 & $5.1(\mathrm{Me})$ & $\begin{array}{l}A, F, L, P, R \\
\text { and } S\end{array}$ & 5.1 years $(\mathrm{Me})$ \\
\hline $\begin{array}{l}\text { Friis et al, }{ }^{28} \text { North } \\
\text { Jutland }\end{array}$ & Cohort & General population (CPR) & 1989-2002 & ICD-10 C22 & $3.3(\mathrm{M})$ & Unspecified & $\geq 2 R x$ \\
\hline Friedman et al, ${ }^{29}$ USA & Cohort & General population (KPMCP) & 1994-2003 & ICD-9-CM 155 & $>2$ & $\begin{array}{l}\text { A, L and S } \\
(97.6 \%)\end{array}$ & $\geq 1 \mathrm{Rx}$ \\
\hline Marelli et $a l_{,}^{30}$ USA & Cohort & $\begin{array}{l}\text { General older population (men } \geq 45 \text { and } \\
\text { women } \geq 55 \text { years; GE Centricity) }\end{array}$ & 1990-2009 & ICD-9 155 & $4.6(\mathrm{M})$ & Unspecified & $\geq 1 \mathrm{cDDD}$ \\
\hline Tsan et al, ${ }^{31}$ Taiwan & Cohort & Patients with HBV infection (NHIRD) & 1997-2008 & ICD-9 155 & $9.9(\mathrm{M})$ & $\begin{array}{l}\mathrm{A}, \mathrm{F}, \mathrm{L}, \mathrm{P}, \mathrm{R} \\
\text { and } \mathrm{S}\end{array}$ & $\geq 28 \mathrm{cDDDs}$ \\
\hline Tsan et al, ${ }^{32}$ Taiwan & Cohort & Patients with HCV infection (NHIRD) & 1999-2010 & ICD-9 155 & $10.7(\mathrm{M})$ & $\begin{array}{l}\mathrm{A}, \mathrm{F}, \mathrm{L}, \mathrm{P}, \mathrm{R} \\
\text { and } \mathrm{S}\end{array}$ & $\geq 28$ cDDDs \\
\hline Khurana et al, ${ }^{33}$ USA & Case-control & General population (VISN) & 1997-2002 & ICD-9 155 & NR & Unspecified & $\geq 1 \mathrm{Rx}$ \\
\hline El-Serag et al, ${ }^{34}$ USA & Case-control & Diabetes patients (VA) & 1997-2002 & ICD-9-CM 155 & $2.4(\mathrm{M})$ & $\begin{array}{l}\text { A, C, F, L, P } \\
\text { and S }\end{array}$ & 1.6 years $(\mathrm{M})$ \\
\hline Chiu et $a l,{ }^{35}$ Taiwan & Case-control & Older patients ( $\geq 50$ years; NHIRD) & 2005-2008 & ICD-9-CM 155 & NR & $\begin{array}{l}A, F, L, P, R \\
\text { and } S\end{array}$ & $\geq 1 \mathrm{cDDD}$ \\
\hline Lai et al, ${ }^{36}$ Taiwan & Case-control & General population (NHIRD) & 2000-2009 & ICD-9-CM 155 & $1.4(\mathrm{M})$ & $\begin{array}{l}A, F, L, P, R \\
\text { and } S\end{array}$ & $\geq 1 \mathrm{Rx}$ \\
\hline Leung et $a{ }^{37}$ Taiwan & Case-control & General population (NHIRD) & 2000-2008 & ICD-9-CM 155 & $4.1(\mathrm{M})$ & Unspecified & $>0.5$ years \\
\hline $\begin{array}{l}\text { Chaiteerakij et al, } \\
\text { USA }\end{array}$ & Case-control & Hyperlipidaemia patients (Mayo Clinic) & 2000-2010 & ICD-9-CM 155 & $>1$ & Unspecified & $\geq 1 \mathrm{Rx}$ \\
\hline
\end{tabular}

Duration of follow-up: When the follow-up periods of statin user and non-user were different, only the shorter period was shown, and all periods were transformed to years.

$\geq 1 \mathrm{cDDD}=$ more than 1 cumulative defined daily dose before the diagnosis of liver cancer; A, atorvastatin; C, cerivastatin; CM, clinical modification; CRP, the Central Population Register of

Danish citizens; F, fluvastatin; GE Centricity, the General Electric Centricity database; HBV, hepatitis B virus; HCV, hepatitis C virus; ICD-9 or ICD-10, International Classification of Diseases,

Ninth Revision or Tenth Revision; IPD, individual patient data; KPMCP, the Kaiser Permanente Medical Care Program in northern California; L, lovastatin; M, mean; Mayo Clinic, Mayo Clinic

(Rochester, MN); Me, median; NHIRD, the Taiwanese National Health Insurance research database; non-statin, non-statin cholesterol-lowering drug(s) only; NR, not reported; P, pravastatin; R,

rosuvastatin; RCT, randomised controlled trials; Rx, prescriptions; S, simvastatin; VA, Veterans Affairs national databases; VISN, Veterans Integrated Service Networks 16 Veteran Affairs

database. 


\begin{tabular}{|c|c|c|c|c|c|c|c|c|}
\hline \multirow[b]{2}{*}{ Studies } & \multicolumn{2}{|c|}{ Intervention/cases } & \multicolumn{2}{|l|}{ Control } & \multirow[b]{2}{*}{$\begin{array}{l}\text { Measurements of } \\
\text { effect estimates }\end{array}$} & \multirow[b]{2}{*}{$\begin{array}{l}\text { Crude RR with } \\
95 \% \text { Cls }\end{array}$} & \multirow[b]{2}{*}{$\begin{array}{l}\text { Adjusted RR with } \\
95 \% \mathrm{Cls}\end{array}$} & \multirow[b]{2}{*}{$\begin{array}{l}\text { Confounders for } \\
\text { adjustment }\end{array}$} \\
\hline & $\begin{array}{l}\text { Number of } \\
\text { event/number } \\
\text { of exposure }\end{array}$ & $\begin{array}{l}\text { Number } \\
\text { of total }\end{array}$ & $\begin{array}{l}\text { Number of } \\
\text { event/ } \\
\text { number of } \\
\text { exposure }\end{array}$ & $\begin{array}{l}\text { Number } \\
\text { of total }\end{array}$ & & & & \\
\hline Emberson et al, ${ }^{19} \mathrm{UK}$ & 35 & 67258 & 33 & 67279 & $\mathrm{RR}$ & $1.06(0.66 \text { to } 1.71)^{*}$ & $1.06(0.66 \text { to } 1.71)^{*}$ & Randomisation \\
\hline $\begin{array}{l}\text { Friis et al, }{ }^{28} \text { North } \\
\text { Jutland }\end{array}$ & 1 & 12251 & 166 & 334754 & OR & NA & 1.16 (0.46 to 2.90$)$ & $1,2,16,21,23$ \\
\hline $\begin{array}{l}\text { Friedman et al } \\
\text { (male), }{ }^{29} \text { USA }\end{array}$ & 32 & 192598 & NA & 1904876 & $\mathrm{HR}$ & NA & 0.49 (0.34 to 0.70$)$ & 16 \\
\hline $\begin{array}{l}\text { Friedman et al } \\
\text { (female), }{ }^{29} \text { USA }\end{array}$ & 10 & 169261 & NA & 1976332 & $\mathrm{HR}$ & NA & $0.40(0.21$ to 0.75$)$ & \\
\hline Marelli et $a l,{ }^{30}$ USA & 13 & 45857 & 24 & 45857 & $\mathrm{RR}$ & $0.31(0.14 \text { to } 0.68)^{*}$ & $0.31(0.14 \text { to } 0.68)^{*}$ & $\begin{array}{l}1-5,14,16-18 \\
26,27\end{array}$ \\
\hline Tsan et al, ${ }^{31}$ Taiwan & 58 & 2785 & 963 & 30628 & $\mathrm{HR}$ & 0.66 (0.51 to 0.86$)$ & $0.47(0.36$ to 0.61$)$ & $1,2,7,8,11,12$ \\
\hline Tsan et al, ${ }^{32}$ Taiwan & 1378 & 35023 & 26505 & 225841 & $\mathrm{HR}$ & $0.42(0.39$ to 0.46$)$ & $0.53(0.49$ to 0.58$)$ & $1,2,7,8,11,13$ \\
\hline Khurana et $a l,{ }^{33}$ USA & NA & NA & NA & NA & OR & NA & $0.52(0.41$ to 0.67$)$ & $1,11,13$ \\
\hline El-Serag et $a l,{ }^{34}$ USA & 447 & 1303 & 2766 & 5212 & OR & 0.46 (0.40 to 0.52$)$ & 0.74 (0.64 to 0.87$)$ & $\begin{array}{l}1-3,6,8,9,11- \\
13,21,24,28\end{array}$ \\
\hline Chiu et $a l,{ }^{35}$ Taiwan & 117 & 1166 & 195 & 1166 & OR & 0.53 (0.41 to 0.69$)$ & $0.62(0.45$ to 0.83$)$ & $\begin{array}{l}1,2,8,9,11,12 \\
20,29\end{array}$ \\
\hline Lai et al, ${ }^{36}$ Taiwan & 255 & 3480 & 1635 & 13920 & OR & 0.61 (0.52 to 0.72$)$ & 0.71 (0.56 to 0.89$)$ & $\begin{array}{l}1,2,8-13,22 \\
24,25\end{array}$ \\
\hline Leung et al, ${ }^{37}$ Taiwan & 26 & 424 & 6851 & 33781 & $\mathrm{HR}$ & 0.45 (0.30 to 0.67$)$ & $0.44(0.28,0.72)$ & $\begin{array}{l}1,2,11,15,20 \\
21,23\end{array}$ \\
\hline $\begin{array}{l}\text { Chaiteerakij et al, }{ }^{38} \\
\text { USA }\end{array}$ & 72 & 165 & 165 & 256 & OR & NA & 0.6 (0.4 to 0.9$)$ & $\begin{array}{l}1-3,8,11,17 \\
22,28,30\end{array}$ \\
\hline
\end{tabular}




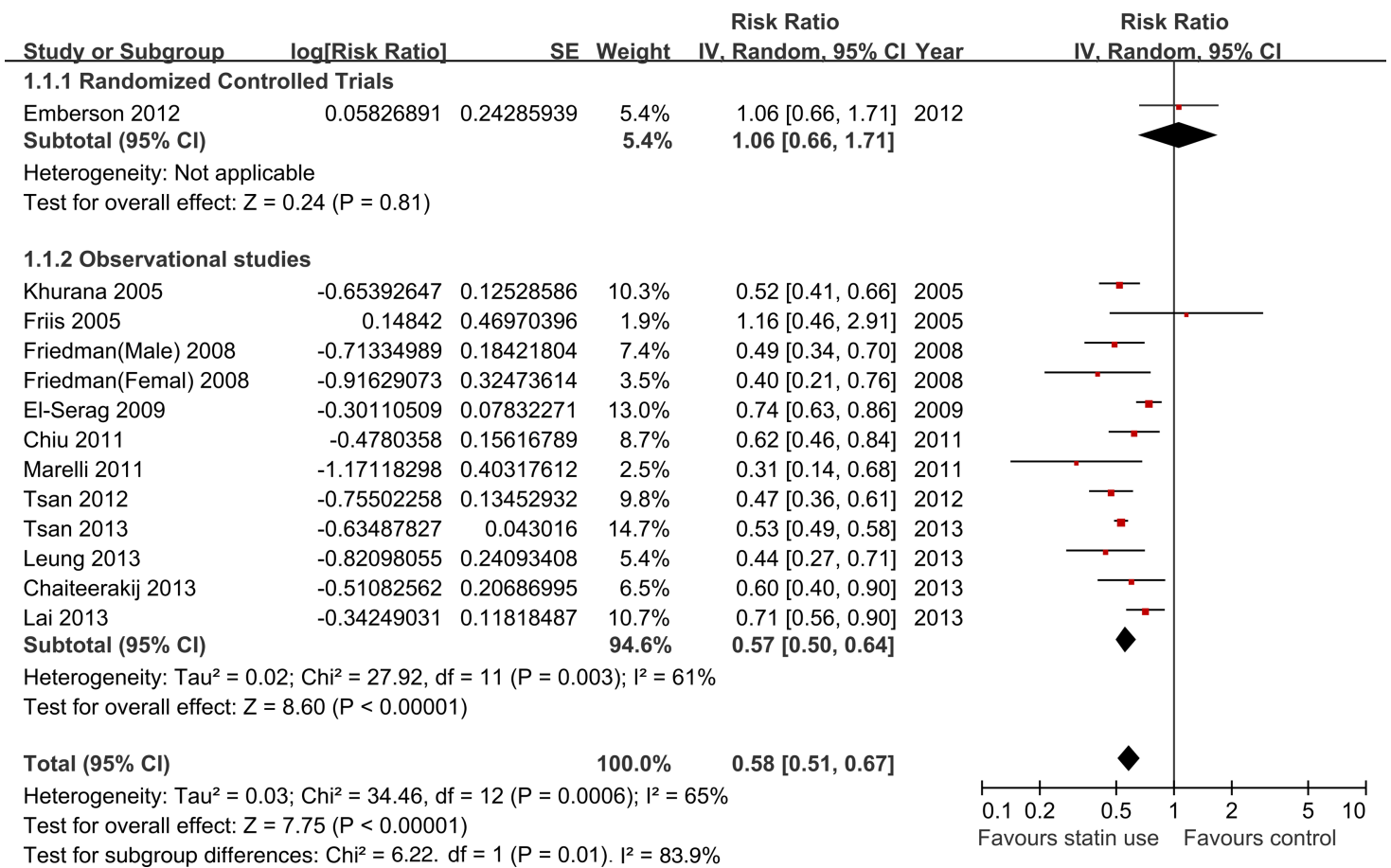

Figure 2 Overall meta-analysis of statin use and liver cancer risk.

Test for interaction showed significant results between subgroups of the RCT and observational studies $\left(\mathrm{P}_{\text {interaction }}=0.01, \mathrm{Z}=2.47\right)$, and between subgroups of the cohort and case-control studies
$\left(P_{\text {interaction }}=0.04, \mathrm{Z}=-2.03\right)$. These results indicated that the difference of the study designs was partly the reason why there was severe heterogeneity in the overall analysis (table 3 ).

Table 3 Subgroup analyses of included studies

\begin{tabular}{|c|c|c|c|c|c|}
\hline \multicolumn{6}{|l|}{ Study design } \\
\hline Subgroup & $\begin{array}{l}\text { Number of } \\
\text { studies (reports) }\end{array}$ & $\begin{array}{l}\text { Summary } \\
\text { RR (95\% Cls) }\end{array}$ & $\begin{array}{l}\text { Heterogeneity, } \\
\mathrm{I}^{2}(\%)\end{array}$ & $\begin{array}{l}\text { Heterogeneity, } \\
\text { p value }\end{array}$ & $\mathbf{P}_{\text {interaction }}$ \\
\hline $\mathrm{RCT}$ & 1 & $1.06(0.66$ to 1.71$)$ & - & - & 0.01 \\
\hline Observational studies & $11(12)$ & $0.57(0.50$ to 0.64$)$ & 61 & 0.003 & \\
\hline \multicolumn{6}{|l|}{ Observational studies } \\
\hline Cohort studies & $5(6)$ & $0.51(0.44$ to 0.58$)$ & 18 & 0.30 & 0.04 \\
\hline Case-control studies & 6 & $0.63(0.54$ to 0.73$)$ & 46 & 0.10 & \\
\hline \multicolumn{6}{|l|}{ Baseline risk of liver cancer } \\
\hline Higher baseline risk & 4 & $0.52(0.47$ to 0.59$)$ & 16 & 0.31 & 0.08 \\
\hline General population & $8(9)$ & $0.63(0.52$ to 0.75$)$ & 59 & 0.01 & \\
\hline \multicolumn{6}{|l|}{ Confounding adjustment } \\
\hline Adequate adjustment & 6 & 0.64 (0.53 to 0.77$)$ & 81 & 0.0001 & 0.08 \\
\hline Inadequate adjustment & $6(7)$ & $0.51(0.43$ to 0.60$)$ & 3 & 0.40 & \\
\hline \multicolumn{6}{|l|}{ Study location } \\
\hline Western studies & $7(8)$ & 0.61 (0.48 to 0.76$)$ & 64 & 0.007 & 0.54 \\
\hline Asian studies & 5 & $0.56(0.48$ to 0.64$)$ & 51 & 0.09 & \\
\hline \multicolumn{6}{|l|}{ Pharmacokinetic } \\
\hline Lipophilic statins & $5(6)$ & $0.57(0.50$ to 0.65$)$ & 50 & 0.08 & 0.86 \\
\hline Hydrophilia statins & 3 & $0.59(0.41$ to 0.84$)$ & 50 & 0.13 & \\
\hline $\begin{array}{l}\text { Higher cumulative dosage of } \\
\text { statin }\end{array}$ & 6 & 0.53 (0.36 to 0.79$)$ & 90 & $<0.0001$ & - \\
\hline
\end{tabular}


In the subgroup analysis of the four studies with higher baseline risk of liver cancer, ${ }^{30-32} 35$ defined as patients with older age, $\mathrm{HBV}$ or $\mathrm{HCV}$ infection, there was a trend towards more decrease of liver cancer risk $(\mathrm{RR}=0.52,0.47$ to $\left.0.59 ; \mathrm{I}^{2}=16 \%, \mathrm{p}=0.31\right)$ than in the other eight studies with general population $192829333436-38$ ( $R R=0.63,0.52$ to $0.75 ; \mathrm{I}^{2}=59 \%, \mathrm{p}=0.01$; see online supplementary figure $\mathrm{S} 3$ ).

We defined the RCT or studies adjusted for at least four of seven important confounders, such as $\mathrm{HBV}$ infection, HCV infection, cirrhosis, alcoholic liver disease, NAFLD, HBV treatment or HCV treatment, ${ }^{39}$ were adjusted adequately. Subgroup analysis of these six studies $^{19} 3132{ }^{34-36}$ found a trend towards less decrease of liver cancer risk $\left(\mathrm{RR}=0.64,0.53\right.$ to $0.77 ; \mathrm{I}^{2}=81 \%$ $\mathrm{p}=0.0001)$ than the other six studies ${ }^{28-30} \quad 33 \quad 37 \quad 38$ $\left(\mathrm{RR}=0.51,0.43\right.$ to $0.60 ; \mathrm{I}^{2}=3 \%, \mathrm{p}=0.40$; see online supplementary figure S4).

Subgroup analyses based on study location found a similar risk reduction of liver cancer in Western countries $\left(\mathrm{RR}=0.61,0.48\right.$ to $\left.0.76 ; \mathrm{I}^{2}=64 \%, \mathrm{p}=0.007\right)$ and in Asian countries $\left(\mathrm{RR}=0.56,0.48\right.$ to $0.64 ; \mathrm{I}^{2}=51 \%, \mathrm{p}=0.09$; see online supplementary figure S5).

Besides the overall RR estimates, some studies reported different RR estimates for different pharmacokinetics and dosage of statin use (see online supplementary table S2). We conducted further subgroup analyses based on these available data.

According to the different pharmacokinetics, statins can be classified as lipophilic statins (atorvastatin, fluvastatin, lovastatin and simvastatin) and hydrophilia statins (pravastatin and rosuvastatin). ${ }^{21}$ Subgroup analysis of lipophilic statins ${ }^{29} 31 \quad 34-36$ found a significant decrease of liver cancer risk ( $\mathrm{RR}=0.57,0.50$ to $0.65 ; \mathrm{I}^{2}=50 \%$, $\mathrm{p}=0.08)$. There was a similar result among users of hydrophilia statins ${ }^{31} 35 \quad 36 \quad(\mathrm{RR}=0.59, \quad 0.41$ to 0.84 ; $\mathrm{I}^{2}=50 \%, \mathrm{p}=0.13$; see online supplementary figure $\left.\mathrm{S} 6\right)$.

Test for interaction showed non-significant results for subgroups with different baseline risk, confounding adjustment, study location or pharmacokinetics $\left(\mathrm{P}_{\text {interaction }}=0.08\right.$, $0.08,0.54$ and 0.86 , respectively; table 3 ). Therefore, there is no strong evidence to support a different preventive effect of statins on liver cancer in these subgroups.

Subgroup analysis of six studies with higher cumulative dose of statin use, defined as statin use over 180 cumulative defined daily doses (cDDDs) or 0.5 years (cumulative duration), showed a trend towards more risk reduction of liver cancer $(\mathrm{RR}=0.53,0.36$ to 0.79$)$, but with a high degree of heterogeneity $\left(\mathrm{I}^{2}=90 \%, \mathrm{p}<0.00001\right.$; see online supplementary figure $\mathrm{S} 7$ ).

\section{DISCUSSION}

This present meta-analysis represents the most comprehensive review to date on the association between statin use and liver cancer risk, by including 12 studies (1 IPD analysis of 22 RCTs, 5 cohort studies and 6 case-control studies) and involving 5640313 participants with 35756 liver cancer cases. Overall, we found that statin use was associated with an over $40 \%$ risk reduction in liver cancer compared with non-users $(\mathrm{RR}=0.58$, 95\% CIs 0.51 to 0.67$)$. This result was in line with the previous three meta-analyses: Singh et $a l^{16}$ included 10 studies and suggested statin users were less likely to develop HCC (OR 0.63, 95\% CIs 0.52 to 0.76 ), Pradelli et at and Zhang et $a t^{41}$ included 5 and 7 observational studies and found a summary RR of 0.58 (95\% CIs 0.46 to 0.74 ) and 0.61 (95\% CIs 0.49 to 0.76$)$, respectively.

The IPD analysis of 22 RCTs showed there is no significant association between statin use and risk of liver cancer. The significant risk reduction of liver cancer among all statin users was seen primarily in the observational studies, and this preventive effect was relatively more convincing in the cohorts than in the case-controls. There were some reasons to explain the different findings between RCTs and observational studies.

First, the exposure period to statins might be shorter than the period to carcinogenesis and the latency to diagnosis in the cohorts and the case-controls. The observational studies defined statin use varying in dosage and duration, from patients who received $\geq 1 \mathrm{cDDD}$ or $>1 \mathrm{Rx}$ of statins to more than 0.5 years (table 1 ). On the other hand, the median period of statin use was 5.1 years in the RCTs. Although there was a trend towards more risk reduction of liver cancer with higher cumulative dose of statin use, this defect might still result in overestimating the cancerpreventive effect of statins in the observational studies.

Second, clinical studies demonstrated that higher serum total cholesterol concentration was associated with decreased risk of liver cancer (see online supplementary table S3). ${ }^{42-44}$ Meanwhile, there were inverse associations between use of non-statin lipid-lowering drugs and risk of liver cancer. ${ }^{35} 38$ Meanwhile, because of the contraindication, statins might not be prescribed to patients with chronic liver disease, which is a known risk factor of liver cancer. Unfortunately, the observational studies included in this analysis seldom adopted these factors for adjustment. Actually, subgroup analysis of studies with adequate adjustment showed a trend towards less risk reduction, indicating the potential of overestimation of this preventive effect by confounders.

Third, the RCTs including a lower risk population (patients with cardiovascular disease rather than $\mathrm{HBV}$ / HCV infection), might not be powerful enough to investigate the liver cancer outcomes, which were much rarer than cardiovascular events. In addition, subgroup analysis of studies with higher baseline risk showed a trend towards a greater decrease of liver cancer risk.

These reasons suggested that the observed modulation of cancer incidence cannot be ascribable to a direct statin-mediated effect ${ }^{20}$; the exposure period, the indication (eg, hyperlipidaemia) and contraindication (eg, chronic liver disease) of statins might overestimate its cancer-preventive effect.

We found similar results in Western and Asian countries, which were different from the meta-analysis conducted by Singh et al, which concluded that the inverse 
association of statins with HCC was stronger in the Asian population. Considering four more studies we included, this difference might be caused by the insufficient data in their meta-analysis. Based on the pharmacokinetics, it is plausible that lipophilic and hydrophilic statins will differ in their liver cancer prevention qualities. ${ }^{21} 22$ However, subgroup analysis of lipophilic and hydrophilic statins showed similar results.

Besides the limitations described previously, there were some other limitations that should be noted. First, a significant heterogeneity was observed in the present meta-analysis, which might result from the difference in study design. Results of subgroup analyses would also be limited by this heterogeneity. Second, the adherence to statin therapy is known to be associated with a healthy lifestyle, which might affect the cancer outcome. ${ }^{45}$ Such information is hard to capture in databases or medical records in the observational studies. ${ }^{46}$ Third, five observational studies were conducted using the Taiwanese National Health Insurance Research Database (NHIRD). ${ }^{31}{ }^{32}$ 35-37 Although they were not all in the same period, these studies might contain overlapping groups of patients. These limitations aforementioned could lead to confounding of overall results from the present study, and should be considered in future studies aiming at confirming the protective effects of statins on human cancer risk.

The strengths of our meta-analysis were as follows: First, we performed a much more comprehensive search and more subgroup analyses, compared with the previous meta-analyses; second, the methodological quality of the included studies was reasonably good; third, publication bias, due to the tendency of not publishing small studies with null results, was not found in our meta-analysis.

Of note, preclinical studies have indicated that statins possess synergism with other therapeutic agents in vitro and in vivo for liver cancer. ${ }^{47}{ }^{48}$ Some clinical studies have also demonstrated that statins would prolong survival in patients with advanced liver cancer (see online supplementary table S4), ${ }^{49-52}$ and are associated with risk reduction of recurrence after curative surgery in patients of HBV-related HCC. ${ }^{53}$ Therefore, considerable interest exists in adjunctive therapy with statins for liver cancer. In fact, there were some RCTs ongoing to determine the effectiveness of pravastatin, when used in combination with sorafenib, in the treatment of liver cancer (see online supplementary table S5).

Currently, physicians are less likely to prescribe statins for patients with chronic liver disease, based on the concerns about statin-induced liver injury. ${ }^{31}$ However, there were number of studies that have demonstrated their safe use and even salutary effects. ${ }^{54-56}$ Meanwhile, the risk of serious statin-related liver injury appears to be no greater than the background incidence of this rare event. ${ }^{57}$ Therefore, considering their benefits for cardiovascular event prevention and the potential effect in liver cancer prevention and treatment, statins should not be denied to these patients.
In conclusion, our results suggest that statin use is associated with significant risk reduction of liver cancer when taken daily for cardiovascular event prevention. However, this preventive effect might be overestimated due to the exposure period, indication and contraindication of statins, and other confounders. Statins might be considered as an adjuvant in the treatment of liver cancer.

Acknowledgements The authors thank Medjaden Bioscience Limited and Gui Lv for assisting in the preparation and revision of this manuscript.

Contributors XC had the original idea. MS, XC and WG worked together to develop an appropriate theoretical framework and design. $X C$ developed the search. MS and XC were involved in the selection process. MS and XC extracted relevant data. XC and WG performed the statistical analysis and all authors were involved in the data interpretation. MS and BN wrote the manuscript draft and revised the draft based on input from the other authors. All authors revised it critically for content and approved the final version.

Funding This research received no specific grant from any funding agency in the public, commercial or not-for-profit sectors.

\section{Competing interests None.}

Provenance and peer review Not commissioned; externally peer reviewed.

Data sharing statement No additional data are available.

Open Access This is an Open Access article distributed in accordance with the Creative Commons Attribution Non Commercial (CC BY-NC 4.0) license, which permits others to distribute, remix, adapt, build upon this work noncommercially, and license their derivative works on different terms, provided the original work is properly cited and the use is non-commercial. See: http:// creativecommons.org/licenses/by-nc/4.0/

\section{REFERENCES}

1. Baigent C, Keech A, Kearney PM, et al. Efficacy and safety of cholesterol-lowering treatment: prospective meta-analysis of data from 90,056 participants in 14 randomised trials of statins. Lancet 2005;366:1267-78.

2. Newman TB, Hulley SB. Carcinogenicity of lipid-lowering drugs. JAMA 1996;275:55-60.

3. Demierre MF, Higgins PD, Gruber SB, et al. Statins and cancer prevention. Nat Rev Cancer 2005;5:930-42.

4. Zeichner S, Mihos CG, Santana O. The pleiotropic effects and therapeutic potential of the hydroxy-methyl-glutaryl-CoA reductase inhibitors in malignancies: a comprehensive review. J Cancer Res Ther 2012;8:176-83.

5. Lonardo A, Loria P. Potential for statins in the chemoprevention and management of hepatocellular carcinoma. J Gastroenterol Hepatol 2012;27:1654-64.

6. Shimoyama S. Statins are logical candidates for overcoming limitations of targeting therapies on malignancy: their potential application to gastrointestinal cancers. Cancer Chemother Pharmacol 2011;67:729-39.

7. Dale $\mathrm{KM}$, Coleman $\mathrm{Cl}$, Henyan $\mathrm{NN}$, et al. Statins and cancer risk a meta-analysis. JAMA 2006;295:74-80.

8. Browning DRL, Martin RM. Statins and risk of cancer: a systematic review and metaanalysis. Int $J$ Cancer 2007;120:833-43.

9. Kuoppala J, Lamminpaa A, Pukkala E. Statins and cancer: a systematic review and meta-analysis. Eur J Cancer 2008;44:2122-32.

10. Baigent $\mathrm{C}$, Blackwell L, Emberson J, et al. Efficacy and safety of more intensive lowering of LDL cholesterol: a meta-analysis of data from 170,000 participants in 26 randomised trials. Lancet 2010;376:1670-81.

11. Undela K, Srikanth V, Bansal D. Statin use and risk of breast cancer: a meta-analysis of observational studies. Breast Cancer Res Treat 2012;135:261-9.

12. Shimoyama S. Statins and gastric cancer risk. Hepatogastroenterology 2011;58:1057-61.

13. Cui $\mathrm{X}$, Xie $\mathrm{Y}$, Chen $\mathrm{M}$, et al. Statin use and risk of pancreatic cancer: a meta-analysis. Cancer Causes Control 2012;23:1099-111.

14. Bansal D, Undela K, D'Cruz S, et al. Statin use and risk of prostate cancer: a meta-analysis of observational studies. PLOS ONE 2012;7:e46691. 
15. Bardou M, Barkun A, Martel M. Effect of statin therapy on colorectal cancer. Gut 2010;59:1572-85.

16. Singh S, Singh PP, Singh AG, et al. Statins are associated with a reduced risk of hepatocellular cancer: a systematic review and meta-analysis. Gastroenterology 2013;144:323-32.

17. Stein EA, Corsini A, Gimpelewicz CR, et al. Fluvastatin treatment is not associated with an increased incidence of cancer. Int $J$ Clin Pract 2006;60:1028-34.

18. Matsushita $\mathrm{Y}$, Sugihara M, Kaburagi J, et al. Pravastatin use and cancer risk: a meta-analysis of individual patient data from long-term prospective controlled trials in Japan. Pharmacoepidemiol Drug Saf 2010;19:196-202.

19. Emberson JR, Kearney PM, Blackwell L, et al. Lack of effect of lowering LDL cholesterol on cancer: meta-analysis of individual data from 175,000 people in 27 randomised trials of statin therapy. PLOS ONE 2012;7:e29849.

20. Gazzerro P, Bifulco M. Statins and cancer in gastroenterology: new insight? Gastroenterology 2013;144:1572-3.

21. Gazzerro P, Proto MC, Gangemi G, et al. Pharmacological actions of statins: a critical appraisal in the management of cancer. Pharmacol Rev 2012;64:102-46.

22. Gronich N, Rennert G. Beyond aspirin-cancer prevention with statins, metformin and bisphosphonates. Nat Rev Clin Oncol 2013;10:625-42.

23. Moher D, Liberati A, Tetzlaff J, et al. Preferred reporting items for systematic reviews and meta-analyses: the PRISMA statement. BMJ 2009;339:b2535.

24. Wells GA, Shea B, O'Connell D, et al. The Newcastle-Ottawa Scale (NOS) for assessing the quality of nonrandomised studies in meta-analyses. http://www.ohri.ca/programs/clinical_epidemiology/ oxford.asp

25. Higgins JP, Thompson SG, Deeks JJ, et al. Measuring inconsistency in meta-analyses. BMJ 2003;327:557-60.

26. METABIAS: Stata module to test for small-study effects in meta-analysis [program], 2009.

27. Altman DG, Bland JM. Interaction revisited: the difference between two estimates. BMJ 2003;326:219.

28. Friis $\mathrm{S}$, Poulsen $\mathrm{AH}$, Johnsen $\mathrm{SP}$, et al. Cancer risk among statin users: a population-based cohort study. Int $J$ Cancer 2005;114:643-7.

29. Friedman GD, Flick ED, Udaltsova N, et al. Screening statins for possible carcinogenic risk: up to 9 years of follow-up of 361,859 recipients. Pharmacoepidemiol Drug Saf 2008;17:27-36.

30. Marelli C, Gunnarsson C, Ross S, et al. Statins and risk of cancer a retrospective Cohort analysis of 45,857 matched Pairs from an electronic medical records database of 11 million adult Americans. J Am Coll Cardiol 2011;58:530-7.

31. Tsan YT, Lee CH, Wang JD, et al. Statins and the risk of hepatocellular carcinoma in patients with hepatitis $B$ virus infection. $J$ Clin Oncol 2012;30:623-30.

32. Tsan YT, Lee CH, Ho WC, et al. Statins and the risk of hepatocellular carcinoma in patients with hepatitis $C$ virus infection. $J$ Clin Oncol 2013;31:1514-21.

33. Khurana V, Saluja A, Caldito G, et al. Statins are protective against hepatocellular cancer in patients with hepatitis $C$ virus infection: half a million US veterans' study. Gastroenterology 2005;128(4, Suppl 2):A714.

34. El-Serag HB, Johnson ML, Hachem C, et al. Statins are associated with a reduced risk of hepatocellular carcinoma in a large cohort of patients with diabetes. Gastroenterology 2009;136:1601-8.

35. Chiu HF, Ho SC, Chen CC, et al. Statin use and the risk of liver cancer: a population-based case-control study. Am J Gastroenterol 2011:106:894-8.

36. Lai SW, Liao KF, Lai HC, et al. Statin use and risk of hepatocellular carcinoma. Eur J Epidemiol 2013;28:485-92.
37. Leung HW, Chan AL, Lo D, et al. Common cancer risk and statins: a population-based case-control study in a Chinese population. Expert Opin Drug Saf 2013;12:19-27.

38. Chaiteerakij R, Yang JD, Harmsen WS, et al. Risk factors for intrahepatic cholangiocarcinoma: association between metformin use and reduced cancer risk. Hepatology 2013;57:648-55.

39. Singh S, Singh PP, Roberts LR, et al. Chemopreventive strategies in hepatocellular carcinoma. Nat Rev Gastroenterol Hepatol 2014;11:45-54.

40. Pradelli D, Soranna D, Scotti L, et al. Statins and primary liver cancer: a meta-analysis of observational studies. Eur J Cancer Prev 2013;22:229-34.

41. Zhang $\mathrm{H}$, Gao $\mathrm{C}$, Fang $\mathrm{L}$, et al. Statin use and risk of liver cancer: a meta-analysis of 7 studies involving more than 4.7 million patients. World J Meta-Anal 2013;1:130-7.

42. Ahn J, Lim U, Weinstein SJ, et al. Prediagnostic total and high-density lipoprotein cholesterol and risk of cancer. Cancer Epidemiol Biomarkers Prev 2009;18:2814-21.

43. Iso $\mathrm{H}$, lkeda $\mathrm{A}$, Inoue $\mathrm{M}$, et al. Serum cholesterol levels in relation to the incidence of cancer: the JPHC study cohorts. Int J Cancer 2009;125:2679-86.

44. Kitahara CM, de Gonzalez AB, Freedman ND, et al. Total cholesterol and cancer risk in a large prospective study in Korea. $J$ Clin Oncol 2011;29:1592-8.

45. Brookhart MA, Patrick AR, Dormuth $\mathrm{C}$, et al. Adherence to lipid-lowering therapy and the use of preventive health services: an investigation of the healthy user effect. Am J Epidemiol 2007; 166:348-54.

46. Boudreau DM, Yu O, Johnson J. Statin use and cancer risk: a comprehensive review. Expert Opin Drug Saf 2010;9:603-21.

47. Kim W, Yoon JH, Kim JR, et al. Synergistic anti-tumor efficacy of lovastatin and protein kinase C-beta inhibitor in hepatocellular carcinoma. Cancer Chemother Pharmacol 2009;64:497-507.

48. Polo MP, Crespo R, de Bravo MG. Geraniol and simvastatin show a synergistic effect on a human hepatocarcinoma cell line. Cell Biochem Funct 2011;29:452-8.

49. Kawata S, Yamasaki E, Nagase T, et al. Effect of pravastatin on survival in patients with advanced hepatocellular carcinoma. A randomized controlled trial. Br J Cancer 2001;84:886-91.

50. Lersch C, Schmelz R, Erdmann J, et al. Treatment of HCC with pravastatin, octreotide, or gemcitabine-a critical evaluation. Hepatogastroenterology 2004;51:1099-103.

51. Graf $\mathrm{H}$, Jungst $\mathrm{C}$, Straub $\mathrm{G}$, et al. Chemoembolization combined with pravastatin improves survival in patients with hepatocellular carcinoma. Digestion 2008;78:34-8.

52. Georgescu EF, Badulescu F, Dumitrescu D, et al. Lovastatin may enhance cytostatic effects of sorafenib in hepatic carcinoma. Primary results of a pilot study. Hepatol Int 2011;5:423.

53. Wu CY, Chen YJ, Ho HJ, et al. Association between nucleoside analogues and risk of hepatitis $B$ virus-related hepatocellular carcinoma recurrence following liver resection. JAMA 2012;308:1906-14.

54. Lewis JH, Mortensen ME, Zweig S, et al. Efficacy and safety of high-dose pravastatin in hypercholesterolemic patients with well-compensated chronic liver disease: results of a prospective, randomized, double-blind, placebo-controlled, multicenter trial. Hepatology 2007;46:1453-63.

55. Nelson A, Torres DM, Morgan AE, et al. A pilot study using simvastatin in the treatment of nonalcoholic steatohepatitis: a randomized placebo-controlled trial. J Clin Gastroenterol 2009;43:990-4.

56. Lewis $\mathrm{JH}$. Clinical perspective: statins and the liver-harmful or helpful? Dig Dis Sci 2012;57:1754-63.

57. Bader T. The myth of statin-induced hepatotoxicity. $A m \mathrm{~J}$ Gastroenterol 2010;105:978-80. 